\section{Social presence and e-commerce B2B chat functions}

E-commerce B2B chat functions

\author{
Jonna Pauliina Koponen
}

Department of Business, University of Eastern Finland, Joensuu, Finland, and

\author{
Saara Rytsy \\ University of Eastern Finland, Joensuu, Finland
}

Received 26 January 2019 Revised 20 June 2019 Accepted 9 December 2019

\begin{abstract}
Purpose - Currently, online chat is in common use in e-commerce. By adding social interaction to the online context, companies hope to increase customers' purchasing intentions. However, previous studies have not investigated how social presence is embedded in online business-to-business (B2B) chat conversations between buyers and sellers. Moreover, the functions of online chat in B2B sales have not been investigated.

Design/methodology/approach - The data was collected at a case company over the course of four years, from which the authors analyzed 157 online chat conversations between buyers $(n=157)$ and sellers $(n=9)$ with a theory-driven thematic analysis. In addition, data from the company's customer relationship management system was collected to specify buyer types.

Findings - The results reveal that social presence was embedded in online B2B chat via buyers' interactive, affective and relationship maintenance responses. Social presence differed depending on the type of buyer, with only existing customers having relationship maintenance responses. E-commerce B2B chat functions can be described as multiple and changing depending on the buyer-seller relationship stage.

Research limitations/implications - Having data only from one case company limits the results to one type of industry.

Practical implications - The results can be used in sales training and when developing online chat services. Originality/value - Results bring scientific utility to B2B sales and marketing research, as the authors build a bridge between social presence, the existing theoretical model on B2B buyer-seller relationship development and online chat as a communication medium. Other researchers may use this understanding when exploring B2B buyer-seller interaction in different digitalized communication media.
\end{abstract}

Keywords Relationship marketing, Online chat, Business-to-business, Buyer-seller interaction, Sales interaction

Paper type Research paper

\section{Introduction}

Online shopping continues to grow in popularity, and new online stores are constantly being established. E-commerce and new forms of computer-mediated communication (CMC) have increased the use of CMC between buyers and sellers (Murphy and Sashi, 2018) and essentially changed buyer-seller interactions in business-to-consumer (B2C) and business-to-business (B2B)

(C) Jonna Pauliina Koponen and Saara Rytsy. Published by Emerald Publishing Limited. This article is published under the Creative Commons Attribution (CC BY 4.0) licence. Anyone may reproduce, distribute, translate and create derivative works of this article (for both commercial and noncommercial purposes), subject to full attribution to the original publication and authors. The full terms of this licence may be seen at http://creativecommons.org/licences/by/4.0/legalcode

This paper forms part of a special section "Digital marketing and business-to-business relationships", guest edited by Charles Hofacker, Kishore Gopalakrishna Pillai, Ismail Golgeci and David Gligor.

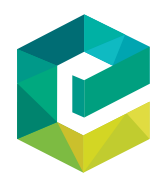

European Journal of Marketing Vol. 54 No. 6,2020 pp. $1205-1224$ pp. 1205-1224
Emerald Publishing Limited 0309-0566 DOI 10.1108/EJM-01-2019-0061 
sales (Arli et al., 2018). Buyers increasingly prefer online interfaces, and almost 75 per cent of B2B buyers prefer purchasing via a website than relying on salespeople, while 93 per cent of them prefer purchasing online once they have decided what to buy (Arli et al., 2018; Hoar, 2015). Moreover, within the past decade, there has been a developing interest in investigating how person-to-person interaction and social presence could be embedded into an online shopping environment (Gefen and Straub, 2004). Social presence and possibilities to interact with sellers are important in e-commerce, as shopping has always been a social activity ( $\mathrm{Lu}$ et al., 2016) and because social presence has been shown to increase customers' initial trust in the website and customer's trust in the seller, as well as enhance customers' purchasing intentions and thereby boost firms' sales (Gefen and Straub, 2004; Ogonowski et al., 2014; Olson and Olson, 2000). Furthermore, it has been shown that social presence influences participants' enjoyment and perceived usefulness of the website (Ogonowski et al., 2014). Social presence is important in online shopping, as anonymous, asynchronous and text-based CMC can hinder the development of interpersonal trust (Sherblom, 2020) between business partners. Moreover, lacking the presence of social elements has been claimed to be one of the major weaknesses that hinders e-commerce growth (Lu et al., 2016). For all these reasons, it is highly important to investigate how social presence is embedded in CMC between buyers and sellers in different online communication channels.

We contribute to existing sales and marketing research by bringing new and original knowledge (Corley and Gioia, 2011) on how social presence is embedded in online B2B chat conversations between buyers and sellers. Furthermore, our results show why buyers join online $\mathrm{B} 2 \mathrm{~B}$ chats and thereby what functions does the online chat serve for B2B buyers. Presently, companies provide online chat facilities to enhance the social aspect of their websites (McLean and Osei-Frimpong, 2017). Online chat allows customers to easily contact a salesperson if they need support or assistance. In addition, online chat enables interaction between previously anonymous customers and salespeople, giving companies the possibility to gain new sales prospects. By focusing on B2B sales context and buyer-seller online chat conversations, we bring new knowledge (Corley and Gioia, 2011) to the field, as most of the previous studies on digital marketing have focused on consumers and B2C sales context (Nicolla and Teresa, 2016; Obal and Lancioni, 2013). There is a severe lack of studies of the social presence and the functions of buyerseller interaction in online chat in B2B sales context (Leek et al., 2017; Ogonowski et al., 2014; Ou et al., 2014). Our approach is important, as B2B business relationships are typically viewed as more relational (i.e. more involved, continuous and interactive) compared to $\mathrm{B} 2 \mathrm{C}$ relationships (Brown et al., 2016), and therefore, it can be assumed that there is a high need for social presence and interaction in digital $\mathrm{B} 2 \mathrm{~B}$ sales.

As well as this, we bring incremental advance (Corley and Gioia, 2011) to the existing $\mathrm{B} 2 \mathrm{~B}$ sales and marketing research by focusing on social presence in online B2B sales interaction as the ability of participants to project themselves socially and affectively in sales interaction. Currently, there is no single definition for social presence and researchers have approached the phenomena from different perspectives. Many of the previous ecommerce studies (Gefen and Straub, 2004; Ogonowski et al., 2014) have defined social presence based on Short et al. (1976) and focused on the capacity of the website to convey a sense of human sociability and warmth (Lu et al., 2016). Instead, other researchers have chosen to define social presence as a multi-dimensional construct including, for example, social presence of the web, perception of others and social presence of interaction with sellers (Lu et al., 2016). In this study, we focus on social presence as interaction with sellers (Caspi and Blau, 2008; Lu et al., 2016). We do not investigate social presence of the website or perceived perception of others in computer-mediated communication. Our focus is on investigating how social presence is embedded in text-based interaction between buyers 
and sellers in online B2B chat. Following Garrison et al. (2001), Garrison and Anderson (2003) and Rourke et al. (1999), we show how social presence is manifested in online discussions in buyers' affective and interactive responses. Furthermore, we are the first to introduce a new category of social presence in the context of online B2B sales, namely relationship maintenance.

Furthermore, we contribute to the existing B2B sales and marketing research by showing how functions of online B2B chat vary for buyers who are at different phases (Dwyer et al., 1987) of the buyer-seller relationship. The extensive exploration of the evolution of B2B relationship selling by Arli et al. (2018, p. 12) suggests that future research should explore whether "technology can be a bridge or a barrier in today's relational selling." Moreover, marketing and sales scholars have been called to investigate different technological tools and how they enable buyer-seller interaction in different phases of the relationship development process because of reduced social and face-to-face time with buyers (Leek et al., 2017). Our study responds to this call and brings scientific utility to the sales and marketing field as we build a bridge between social presence (Garrison et al., 2001; Garrison and Anderson, 2003; Rourke et al., 1999), the existing theoretical model on B2B buyer-seller relationship development (Dwyer et al., 1987) and online chat as a communication medium (Ogonowski et al., 2014). As a communication medium, online chat has a high level of social presence (Ogonowski et al., 2014, p. 483), and it should thereby enhance buyer-seller interaction. However, it is not known how buyer-seller interaction varies in $\mathrm{B} 2 \mathrm{~B}$ online chat conversations when buyers are at different phases of the relationship. In addition, in our study, we bring about a new understanding of what kinds of functions the online chat has at different phases of the buyer-seller relationship development process and how social presence is embedded in online chat conversations with different types of buyers. Our results are scientifically useful, as we are the first to build these connections, and other researchers may use this understanding when exploring B2B buyer-seller interaction in different digitalized communication media.

Fourth, the results of this study are practically useful (Corley and Gioia, 2011), as companies offering a chat service on their websites can use our results in their sales training. Companies should train their B2B chat salespersons well enough to be able to answer complex questions professionally. $\mathrm{B} 2 \mathrm{~B}$ chat salespersons should be able to recognize existing buyers and react to their need for social disclosure online. Moreover, the results can be used to enhance the content of the company's website (e.g. add frequently asked questions and answers) and when testing the use of chatbots in B2B sales. Next, we present our theoretical background. Following that, we introduce our method and analysis, followed by our results and discussion. Finally, we present theoretical and practical implications.

\section{Theoretical foundation}

\subsection{Online chat in e-commerce}

During the past decade, people have become interested in how aspects of social interaction, such as social presence, could be embedded in online environments to enhance customers' trust and thereby sales performance (Gefen and Straub, 2004; Olson and Olson, 2000). Experts in online business have recognised that customers should not be ignored when they visit a website, leading to the development of personalized websites. Currently, several online stores provide online chat functionality (McLean and Osei-Frimpong, 2017) to enhance the social aspects of their websites. Online chat, which is often entitled live chat or instant messaging, is a computer-mediated service offered to online businesses who want to enhance their online customer service (Chattaraman et al., 2012). Indeed, online chat is viewed as a cost-effective way to assist customers, as it allows customers to search for 
service-related information and contact a human representative from an organization, who can answer their questions (McLean and Osei-Frimpong, 2017). This definition clearly emphasizes that the role of online chat is to enhance the buying process by focusing on business-related discussion.

Previous studies have revealed that customer satisfaction can be increased by providing access to service personnel via websites (Yoon, 2010), to increase customers' trust in a website by providing a social presence via online chat (Ogonowski et al., 2014) and to encourage repeat visits by customers via virtual agents (Etemad-Sajadi, 2014). However, research focusing on online chat in the B2B sales context is scarce (Arli et al., 2018). As B2B sales and B2C sales processes differ, an in-depth understanding of the functions of online chat in $\mathrm{B} 2 \mathrm{~B}$ sales is needed. The $\mathrm{B} 2 \mathrm{~B}$ sales process is longer and more complex than in $\mathrm{B} 2 \mathrm{C}$ sales, there are relatively fewer actors and interdependence is more common (Akrout and Diallo, 2017; Dubinsky, 1981; Homburg et al., 2011). Trust is usually critical in B2B sales, as is developing a relationship between buyer and seller (Dwyer et al., 1987; Crosby et al., 1990; Palmatier et al., 2013). Therefore, the functions of online chat may be somewhat different to what has already been identified in the B2C context.

Live online chat provides opportunities for two-way synchronous communication, and many organizations and companies provide online chat on their websites to offer support to their customers (Truel and Connelly, 2013; McLean and Osei-Frimpong, 2017). Some prior studies have investigated the functions of online chat in the $\mathrm{B} 2 \mathrm{C}$ context. Online chat is usually provided to give customers the chance to ask questions, answer their queries and help them overcome problems and to give them help in navigating the website (McLean and Osei-Frimpong, 2017; Truel and Connelly, 2013). According to Chattaraman et al. (2012), online chat has three key functions: search support, navigational support and basic decision support. Previous studies have found that customers use online chat to collect information from an expert service provider, as well as to shorten the amount of time they spend on a task (Chattaraman et al., 2012; Truel and Connelly, 2013). However, the functions of buyerseller interaction in online $\mathrm{B} 2 \mathrm{~B}$ chat have not been explored.

\subsection{Social presence}

Companies usually provide live and interactive online chat in e-commerce to bring a greater level of social presence (Ogonowski et al., 2014). Currently, there is no single definition for social presence, and researchers have approached the phenomena from different perspectives. Many of the previous e-commerce studies (Gefen and Straub, 2004; Ogonowski et al., 2014) have adopted a one-dimensional model of social presence, basically defining social presence based on Short et al. (1976) and focusing on the capacity of the website to convey a sense of human sociability and warmth (Lu et al., 2016). Sallnäs et al. (2000, p. 462) state that "social presence refers to the feeling of being socially present with another person at a remote location." Traditionally, social presence theory states (Short et al., 1976) that the degree of social presence varies depending on the communication medium. For example, different communication media have different capacities to transmit information through verbal and non-verbal communication (Short et al., 1976). According to Knapp (1972), verbal communication means the spoken or written word, whereas non-verbal communication refers to kinesics (e.g. movements of the head, hand, arm and foot, posture, gestures and facial expressions), paralanguage (e.g. voice pitch, volume, frequency, speech rate and pauses), physical contact (touching), proxemics (interpersonal spacing), physical characteristics (e.g. skin colour, body shape, attractiveness), artefacts (e.g. jewellery, clothes) and environmental factors (referring to the influences of the physical setting). In other words, different communication media have different degrees of capacity to transmit non- 
verbal and verbal communication, and communication is appropriate and effective if the communication channel has the social presence required for the task (Sallnäs et al., 2000). Social presence has a continuum (Short et al., 1976) from face-to-face interaction (with the most social presence), all the way to text-based, written communication (with the least social presence). Tasks that involve interpersonal communication skills, such as negotiation or resolving conflicts, require higher social presence, and tasks that require routine exchange of information require less social presence (Sallnäs et al., 2000; Short et al., 1976). As B2B sales involve various areas of competence, for example, identifying buyers' needs and problems, offering solutions, negotiating and handling complaints, B2B sellers need strong interpersonal communication skills (Koponen, Julkunen and Asai, 2019). Therefore, it is assumed that B2B sales interaction requires a vast amount of social presence also in online context.

Alternatively, other researchers have chosen to define social presence a multidimensional construct including, for example, social presence of the web, perception of others and social presence of interaction with sellers (Lu et al., 2016). In this study, we focus on social presence as interaction with sellers (Caspi and Blau, 2008; Lu et al., 2016). We do not investigate social presence of the website or perceived perception of others. Our focus is on investigating how social presence is embedded in text-based interaction between buyers and sellers in online B2B chat. More precisely, based on Garrison et al. (2001), Garrison and Anderson (2003) and Rourke et al. (1999), we define social presence in interaction with buyers and sellers as the ability of participants to project themselves socially and affectively in sales interaction. Researchers who have also defined social presence as participants' ability to project themselves socially and affectively in online discussions (Garrison et al., 2001; Garrison and Anderson, 2003; Rourke et al., 1999) have suggested three categories of how social presence is manifested in online discussions. These are: affective responses (e.g. expressing humour, emotions and self-disclosure), interactive responses (e.g. replying to others, referring to other's messages, expressing agreement, asking questions) and cohesive responses representing activities that build and sustain a sense of group commitment (e.g. addressing participants by name, greetings) (Rourke et al., 1999). These categorizations have been applied when investigating online group discussions (Rourke et al., 1999). Even though previous studies have investigated social presence as a projection of the self in online learning environment (Garrison et al., 2001; Garrison and Anderson, 2003; Rourke et al., 1999), we apply the same theoretical idea in a professional B2B online sales setting. This is because this definition focuses on actual observed communication (in our case text-based online chat conversations) instead of the potential of the medium to transfer social cues, which was the original idea by Short et al. (1976).

\subsection{Interpersonal communication and buyer-seller relationship}

Dyadic human interaction is often thought of as a necessity when creating and maintaining long-term customer relationships (Elo et al., 2015). The marketing literature has addressed the importance of interpersonal communication in developing long-term business relationships (Celuch et al., 2006; Dwyer et al., 1987; Mason and Leek, 2012; Vadi and Suuroja, 2006). Interpersonal communication is a "process involving a dyad or small number of people in which actors create meanings through verbal and nonverbal message behaviours" (Baxter and Braithwaite, 2008, p. 3). Via interpersonal communication, people negotiate meanings and identity and establish relationships (Baxter and Braithwaite, 2008). Through reciprocal communication, it is possible to coordinate activities and for actors to develop trust, shared values and understanding (Hung and Lin, 2013; Stanko et al., 2007). Several studies have shown that effective communication is also connected with the 
perceived quality of the buyer-seller relationship and with the development of commitment as well as satisfaction between B2B sales partners (Hung and Lin, 2013; Stanko et al., 2007; Weitz and Bradford, 1999).

Traditional buyer-seller relationships in B2B sales enable buyers to have continuous contact with a salesperson who they are familiar with (Dwyer et al., 1987), whereas online commerce often lacks this type of continuous buyer-seller interaction (Gefen and Straub, 2004). As customers rarely have direct contact with the seller in online commerce, Reichheld and Schefter (2000) argue that customers have to rely on technology and the organization rather than a particular seller. To enhance their social presence, companies sometimes use several social presence tools, such as socially rich photographs, instant messaging with live customer support, online chat boxes with text or video chat boxes with an online customer service person (Gefen and Straub, 2004; Ogonowski et al., 2014). In online live chat boxes, an expert or technician is available when a customer enters the chat to answer questions about services or products (Ogonowski et al., 2014). Online chat has a high level of social presence (Ogonowski et al., 2014, p. 483) and it should thereby enhance buyer-seller interaction. However, it is the users of the medium (in this case buyers and sellers) who actually consider the amount of social presence required for the task and whether their task can be handled through online chat.

Relationship marketing literature conceptualizes the development of buyer-seller relationships as an on-going process that evolves through stages (Dwyer et al., 1987). In their ground-breaking article, Dwyer et al. (1987) propose a sequence of stages that the buyer-seller relationship passes through which include: awareness, exploration, expansion and commitment. They also acknowledged the dissolution of the relationship, which may occur at any stage of the relationship. According to Dwyer et al. (1987) in the first phase (awareness), the main function is in recognizing potential exchange partners. The situational proximity of the partners advances awareness. In the second phase (exploration), dyadic interaction occurs, and a gradual increase in interdependence reflects bilateral probing and testing. In the third phase (expansion), mutual satisfaction between partners is possible via customized role performance. There is deeper interdependence between the buyer and seller and additional gratifications are also sought from the partners. In the fourth phase (commitment), shared values and/or contractual mechanisms ensure sustained interdependence between business partners. There are significant mutual inputs in the process. The partners resolve conflicts and adapt to each other. Finally, dissolution refers to a partner's possibility of withdrawal at any stage of the relationship. Basically, withdrawal is implicitly present throughout the relationship development process. Later findings have also shown that, for example, service provider-client relationships (Price and Arnould, 1999) and sales agent-business partner relationships (Grayson, 2007) can develop into friendships. This shows that even though buyer-seller relationships are highly task-oriented, as they become long-term relationships, they may share some similarities with other personal relationships. Moreover, as buyer-seller relationships evolve from transactional relationships toward long-term relationships, there are needs for a social presence and deeper interaction between the parties.

Furthermore, buyers who are in different phases of the B2B customer-relationship development process might have different requirements from online chats. They might also use online chats for different purposes, as in the beginning of the relationship the need for mutual information sharing is high (Andersen, 2001) and thereby also the demand for social presence could be assumed to be high. According to Andersen (2001), as the customer relationship evolves, continuing communication leads to the development of communication rules and norms between parties. Understanding, interpreting and responding becomes easier, and also the feelings, interests and intentions of both parties are acknowledged (Andersen, 2001). Therefore, buyers who are in deeper phases of the relationship might also 
have a need for personal sharing. Still, previous studies have not explored how social presence is embedded in online B2B chat conversations between sellers and buyers who are in different phases of the relationship, as we do in this research.

\section{Method}

The aim of this study is to understand how social presence is embedded in online B2B chat conversations between sellers and buyers who are at different phases of the customer relationship. Moreover, we explore what type of functions the online chat serves in the B2B sales context for buyers who are at different phases of the customer relationship. Therefore, we chose a single case study approach to gain an in-depth understanding of the phenomena (Yin, 2009). The aim of a case study is to acknowledge the uniqueness of the case and to afford an in-depth, contextualized understanding of it (Eriksson and Kovalainen, 2008; Yin, 2009). We propose the following research questions:

$R Q 1$. How is social presence embedded in online B2B chat conversations between salespeople and buyers who are at different phases of the customer relationship?

$R Q 2$. How do the functions of online B2B chat vary for buyers who are at different phases of the customer relationship?

\subsection{Data collection}

The empirical research data was collected at the case company in 2014-2017 using existing online B2B chat conversations between buyers and sellers. The case company was selected by searching for a company which would offer us possibilities to collect data in natural settings right after the $\mathrm{B} 2 \mathrm{~B}$ online chat service was established. Therefore, the online $\mathrm{B} 2 \mathrm{~B}$ chat conversations in this research have not been produced for the purposes of any research; rather, our data was collected in a natural setting. The case company is a high-technology firm which offers software as a service (SaaS) (Obal, 2013) online via its own website. It offers these cloud-based services to domestic and international B2B buyers, who can purchase the service online. The case company has a technology team, a marketing and sales team and a management and finance team. The typical buyer is a small- or mediumsized enterprise (SME) that has online sales.

To find new prospects and thereby improve their sales, the case firm decided to add online chat features to their website in 2014. The online chat feature was available during office hours (from 8 a.m. until 4 p.m.), it provided immediate communication and it was purely text based (no video available). Sellers (hereafter called chat salesperson) were asked to respond to all chat visitors and pass possible prospects on to the sales team, which consisted of more experienced solution sellers. The chat salespersons had received sales training from the case company. The online chat conversations were recorded using chat software applications that automatically saved the data as conversations. A total of 157 chat conversations were downloaded as Excel documents that showed the producer of the data (buyer or seller). A conversation means chat messages (sentences) are written by one of the parties into a chat box and are then followed by the other party until the end of that conversation. Each individual chat message line was identified as a communication unit for analysis and thereby altogether 2,251 communication units were identified. One conversation between the buyer and the seller consisted of around ten communication units. The buyers were aware that the data are recorded, as the case firm's privacy policy clarifies that online chat data are recorded and it can be used for research purposes (Eriksson and Kovalainen, 2008). The company's customer relationship management data was used to
E-commerce $\mathrm{B} 2 \mathrm{~B}$ chat functions 
$\mathrm{EJM}$

54,6

1212

verify necessary information related to buyer types. This was done by chat salespeople after every chat conversation because the company's online chat system was not able to recognize customer types at the beginning of the conversation.

\subsection{Data analysis}

First, we selected only chat conversations including at least one question and one reply for the analysis, and we eliminated all other data (e.g. where the buyer just says "Hello" and then leaves the chat). This left us with 157 online chat conversations for the analysis, thus omitting 23 chat conversations (or single messages). Second, we organized the data based on buyer types. Even though the case company had established the online chat service for developing sales prospects, we found that as well as new buyers $(n=101)$, existing prospects $(n=19)$ and existing buyers $(n=37)$ used the online chat service. Information regarding buyer types was found from the company's customer relationship management data. The company used the term new buyer referring to buyers who they had not had any prior communication with. Referring to Dwyer et al. (1987), we identified that these buyers are at the awareness phase of the buyer-seller relationship. The company named existing prospect to describe buyers with whom they had already interacted but without concrete sales. Related to Dwyer et al. (1987), we identified that these buyers were at the exploration phase of the buyer-seller relationship. Existing buyers (as defined by the company) were those who had bought the company's service and had long-term customer relationships with the case company. Referring to Dwyer et al. (1987), we labelled these buyers to be at the expansion phase of the buyer-seller relationship. The buyer types are summarized in Table I.

All the online chat conversations were then coded for social presence and their function using a thematic analysis by classifying the message content (Braun and Clarke, 2006; Leek et al., 2017). According to Braun and Clarke (2006, p. 79), "thematic analysis is a method for identifying, analyzing and reporting patterns (themes) within data." In the analysis, we followed the principles laid out by Braun and Clarke (2006). We applied theoretical thematic analysis, which was driven by our research questions (Braun and Clarke, 2006, p. 84). In the first phase, we familiarized ourselves with our data. We carefully read the online chat conversations (in written text format) to gain a holistic picture of the data.

In the second phase, we divided the data into three data sets based on buyer type (Table I: new buyers; existing prospects; and existing buyers). We then generated initial codes from each of the data sets related to social presence. As Garrison et al. (2001), Garrison and Anderson (2003) and Rourke et al. (1999) suggest, we applied their idea of categorization in the analysis by using three categories of how social presence can be manifested in online discussions. Their categories were affective responses (e.g. expressing emotions and selfdisclosure), interactive responses (e.g. replying to others, referring to other's messages,

Table I.

Buyer types in the data
Information from the case company regarding the buyer

No proven prior interaction with the case company

New buyer

Existing prospect

Potential end-client with some prior interaction with the company

Existing buyer
Current paying end-client or a partner.

Long-term business relationship with much prior interaction with the company
Relationship phase based on Dwyer et al. (1987)

Awareness phase in B2B buyer-seller relationship

Exploration phase in B2B buyer-seller relationship

Expansion phase in B2B buyer-seller relationship 
expressing agreement, asking questions) and cohesive responses (e.g. addressing participants by name, greetings). We systematically coded the data sets, and then we separated the codes under the themes of affective responses, interactive responses or cohesive responses in each of the three data sets. We were able to find interactive and affective responses from the data, though cohesive responses were not particularly present. In previous studies, cohesiveness referred to activities that build or sustain a sense of group commitment (Rourke et al., 1999), and this was found to be applicable when investigating online group discussions. However, in our study, we investigated a dyadic interaction rather than group communication and our interest was in buyer-seller relationship rather than in group cohesiveness. Therefore, we added a new category in the analysis, "relationship maintenance," which referred to responses that aimed to maintain the existing customer relationships (e.g. small talk, greetings and bringing in another client). Bringing in another client was thought to represent willingness to maintain the relationship, as the buyers wanted to let their clients know about the case company's SaaS services.

In the third phase, we analyzed the codes applied in the social presence analysis to discover if we could find potential themes related to functions of the online chat for the buyers. This was indeed possible, as, for example, their vast amount of questions served different functions. Furthermore, we named these functions. Finally, we counted the number of utterances in each theme, and we selected relevant excerpts from our data to illustrate social presence as well as the functions of the online B2B chat for buyers.

\section{Results}

Here, we present the results from our study which are organized in Figure 1 according to the main themes that correspond to the research questions. First, the number of buyers using the online B2B chat features came to 157 . These were categorized as new buyers $(n=101)$, existing prospects $(n=19)$ and existing buyers $(n=37)$, based on their customer relationship phase (Dwyer et al., 1987). With all the above-mentioned buyers, online chat conversations included social presence referring to interactive and affective responses. However, the results show that only with existing buyers did some of the online chat conversations include relationship maintenance responses. Furthermore, our results reveal how the functions of online B2B chat varied depending on the types of buyers. The results are shown in Figure 1 and elaborated thereafter.

\subsection{Social presence and functions of the online business-to-business chat for new buyers}

For new buyers $(n=101)$, social presence was embedded in online B2B chat conversations through interactive and affective responses. Interactive social presence emerged when buyers were asking the seller several different kinds of questions in online chat (Figure 1). Most of these questions were related to gaining more precise information on SaaS services (such as service packages or how the service works) or pricing. A typical example of interactive social presence focusing on an information search is shown in the next quotation from the data:

New buyer: Hi! Can I have some assistance here?

Chat salesperson: Yes of course, how can I help you?

New buyer: I am searching for information on your services. Do I select one service package or should I combine them? 
EJM

54,6

1214

$\left.\begin{array}{llll}\hline \begin{array}{l}\text { Buyer type } \\
\text { \& number } \\
\text { of buyers }\end{array} & \begin{array}{l}\text { Social } \\
\text { presence }\end{array} & \begin{array}{l}\text { Code of social presence } \\
\text { (number of units) }\end{array} & \begin{array}{l}\text { Function of the online chat } \\
\text { for the buyer }\end{array} \\
\hline \begin{array}{l}\text { New buyer } \\
(n=101)\end{array} & \text { Interactive } & \begin{array}{l}\text { - Asking for more information about } \\
\text { SaaS services }(75) \\
\text { - Asking about pricing }(20)\end{array}\end{array}\right\} \quad$\begin{tabular}{l} 
Searching for information \\
\hline
\end{tabular}

-Asking questions and figurin

- Asking questions and figuring out if the service meets the customer's specific needs (50)

- Asking for customized solutions (4)

Problem-solving

- Asking the salesperson to contact the customer via phone or email (39) - Asking for registration for a seminar (3)

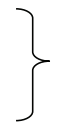

Further interaction

- Customer asking to buy SaaS services (2)

t Purchasing

Affective - Expressing positive emotions (3)

- Expressing negative emotions (13) $\}$ Customers' feedback

\begin{tabular}{|c|c|c|c|}
\hline & Affective & - Expressing positive emotions (3) & \\
\hline & & - Expressing negative emotions (13) & Customers' feedback \\
\hline $\begin{array}{l}\text { Existing } \\
\text { prospect } \\
(n=19)\end{array}$ & Interactive & $\begin{array}{l}\text { - Asking for more information on } \\
\text { SaaS services (6) } \\
\text { - Asking about pricing (3) }\end{array}$ & Searching for information \\
\hline & & $\begin{array}{l}\text { - Asking for the salesperson to } \\
\text { contact the customer via phone or } \\
\text { email }(6) \\
\text { - Asking for registration for a seminar } \\
\text { (2) }\end{array}$ & Further interaction \\
\hline & & $\begin{array}{l}\text { - Customer asking to buy SaaS } \\
\text { services or start collaboration with } \\
\text { the case company ( } 2 \text { ) }\end{array}$ & Purchasing \\
\hline & Affective & - Expressing negative emotions (4) & Customers feedback \\
\hline $\begin{array}{l}\text { Existing } \\
\text { buyer } \\
(n=37)\end{array}$ & Interactive & $\begin{array}{l}\text { - Asking for more information about } \\
\text { SaaS services (27) } \\
\text { - Asking about pricing (8) }\end{array}$ & Searching for information \\
\hline & & $\begin{array}{l}\text { - Asking for the salesperson to } \\
\text { contact them via phone or email (28) }\end{array}$ & Further interaction \\
\hline & & $\begin{array}{l}\text { - Asking questions and figuring out if } \\
\text { a new service meets the customer's } \\
\text { needs (11) } \\
\text { - Asking for a professional opinion } \\
\text { on other service providers ( } 2 \text { ) }\end{array}$ & Problem-solving \\
\hline & Affective & - Self-disclosure (9) & Become acquainted \\
\hline & & - Expressing negative emotions (13) & Customers' feedback \\
\hline & $\begin{array}{l}\text { Relationship } \\
\text { maintenance }\end{array}$ & $\begin{array}{l}\text { - Asking for a solution for the } \\
\text { customer's customers (13) }\end{array}$ & $\begin{array}{l}\text { Bringing in another potential } \\
\text { client }\end{array}$ \\
\hline & & $\begin{array}{l}\text { - Sending greetings to certain people } \\
\text { in the company by his/her name ( } 7) \\
\text { - Small talk (5) }\end{array}$ & Socializing \\
\hline
\end{tabular}

Figure 1.

Results of social presence and different functions of online business-tobusiness chat conversations for buyers 
Chat salesperson: This decision is up to you.

E-commerce

New buyer: What is the cost of each package?

B2B chat functions

Chat salesperson explains the price and conversation continues.

Interestingly, buyers also expressed rather detailed business problems to which they were searching for solutions. For example, they expressed having a problem to integrate different software and they were asking the chat seller if the case company could do the integration. When the chat salesperson was successfully able to help the buyers, they found a positive solution for their problems. Typical examples related to problem-solving are shown in next two examples.

Example 1

New buyer: "Hi, I am trying to figure out how I could connect my ERP [System Z] with [Webstore 1] or [Webstore 2]. I need to get my webstore and my inventory synced. Is it possible to get this kind of synchronization done in real-time?"

Chat salesperson: "Yes, I checked the service technical information. It looks like we can do the synchronization."

The online chat conversation continues.

Example 2

New buyer: "Hello, do you happen to have any experience of Software A and Software B? I mean, how do you connect these programs? Currently we do it all manually, however, it is getting too hard."

Chat salesperson: "Hello! Yes, it is possible to connect these programs, so this should be doable! Please tell me what company you represent?"

The online chat conversation continues.

Furthermore, many buyers asked the salesperson to contact them via another communication channel (e.g. phone or email). This way the chat sellers were able to start building the business relationship by giving solution sellers an email address and/ or phone number to the new buyers and by proposing setting a meeting for further interaction with another salesperson from the company who was a more experienced solution seller. Usually, the chat salesperson asked for the buyer's contact information (name, name of the company, phone number and email address) to set a meeting. In most cases, the chat salesperson was able to help the new buyers or pass them on to a solution seller (in 93 of the 101 chat conversations between new buyers and chat salespersons). In eight chat conversations, the chat seller was not able to help the new buyer. This was shown with expressions, such as, "I don't fully know whether that particular function is included in [Program X]" or "I could not find any information about that, so I don't know." Thereafter, they asked the buyer if they could put them in touch with a more experienced salesperson. Additionally, two new buyers wanted to make a purchase by having a conversation with a chat seller.

Affective social presence emerged when new buyers expressed positive and negative emotions in online B2B chat conversations. Basically, these emotional expressions were related to either having a good or bad customer service. New buyers gave positive feedback about the informative website and good service. On the other hand, they complained if they had a problem with the website or if it did not provide enough in-depth information related 
to SaaS services. However, self-disclosure or the use of humour (Rourke et al., 1999) did not exist in online B2B chat conversations between new buyers and sellers.

Functions of the online B2B chat for new buyers (Figure 1) were found when we analyzed interactive and affective social presence further. As a result, we found six functions which were searching for information, problem-solving, starting interaction with the solution seller, purchasing and giving feedback. New buyers mainly used online chat to ask how to find information on the website or to ask for more information about the SaaS services and how well the services met their needs and solved their problems.

4.2 Social presence and functions of the online business-to-business chat for existing prospects For existing prospects $(n=19)$, social presence was embedded in online B2B chat conversations through interactive and affective responses. Interactive social presence emerged as requesting different kinds of questions from the seller in online B2B chat. As Figure 1 shows, existing prospects' questions were mainly related to case company's services and pricing. Furthermore, existing prospects asked the seller to contact them via another communication channel or they expressed their willingness to make a purchase/ start collaboration with the company. In most cases, the chat salesperson was able to help the prospects or forward them to company's solution seller (17 of the 19 chat conversations between new prospects and chat salespersons). In two chat conversations, the focus was on negative feedback, and the prospect's situation remained unresolved.

Affective social presence was shown only through negative emotional expressions focusing on customer complaints. The existing prospects mainly complained if the seller had not called or contacted the prospect as promised, as the next example from the data illustrates.

Existing prospect: "You have not bothered to call me, so we have decided to take another provider's service."

Chat salesperson: "I have sent an urgent request to our solution seller to contact you. I will call the seller again and ask him to speed up. Can I help you in any other ways?"

Existing prospect: "I think it is too late because you don't seem to want to sell me anything!"

Chat salesperson: "Of course we want to sell! Our sales expert will call you in a minute, I was able to catch him now."

Existing prospect: "It would be best if you had an expert in the chat so you would not need to act as a useless intermediary:)"

Chat salesperson: "Thank you for your feedback. We will try to develop our services."

Functions of the online B2B chat for existing prospects were further analyzed and the results showed that the functions were related to searching for information, having further interaction with a solution seller, purchasing and giving feedback. Figure 1 shows that, as with new buyers, existing prospects had pretty similar reasons to use the online chat. However, they did not express specific business problems into which they would have been searching for a solution.

4.3 Social presence and functions of the online business-to-business chat for existing buyers For existing buyers $(n=37)$, social presence was embedded in online B2B chat conversations through interactive, affective and relationship maintenance responses. 
Existing buyers included currently paying clients or partners who had prior interaction with the case company. In most of the chat conversations (in 29 of the 37 online chat conversations between chat salespersons and existing buyers), the chat salespersons were able to help the existing buyers or forward them to a solution seller. Interactive social presence emerged when existing buyers were asking questions related to the case company's SaaS services and pricing. They also asked if the seller could contact them via another communication channel. Furthermore, they wanted to discuss how the new service they had already bought had met their expectations and fulfilled their needs. In addition, some buyers requested a professional opinion regarding other service providers which shows respect toward the case company's expertise.

Affective social presence was shown as buyers' self-disclosure and in expressing negative emotions. As with the two other buyer types, negative emotions were related to customer complaints, particularly if they could not reach the solution seller, when the solution seller had not called or if they had problems with a SaaS service. Notably, self-disclosure existed only in online B2B chat discussions with existing buyers and chat salespeople. Self-disclosure was social in nature, not exchange-specific (Jacobs et al., 2001); that is, the buyers voluntarily revealed personal information about themselves which was not related to sales, exchange or transaction, as the next example illustrates.

[At the end of earlier discussion]

Existing buyer: "I will try to be available all day. You know, I am in Spain right now and mobile connections are not always good here, so if you can't get through straight away you can try to call again."

Chat salesperson: "Yes! I forwarded this information already to Matt. He will contact you today. (-) Have a wonderful holiday in Spain!"

Existing buyer: "It is so great to have this kind of job. I can move around, so it does not really matter where I am. :) Thanks!"

Chat salesperson: "Yes, that's the best part of remote working. I wish the sun was shining here! You know, in Helsinki it's snowing today."

Relationship maintenance social presence was shown in existing buyers' small talk, sending greetings to certain people in the company by his/her name and in asking for a solution for the customer's customers. Compared to other buyer types, relationship maintenance was only shown in B2B online chat discussions between sellers and existing buyers; small talk existed when buyers entered the only chat room and came to talk without any specific taskrelated purpose, as the next example shows:

Existing buyer: "Hello, it is me [John] from [Company A]:)"

Chat salesperson: "Hello. How are you doing? It’s [Amanda]."

Existing buyer: "Hi!: D/I’m ok, thanks:)/How about you?"

Chat salesperson: "I'm fine too! I am chatting and so many things are going on at the same time... By the way, did you get our email?" 
$\mathrm{EJM}$

54,6

\section{8}

Existing buyer: "This chat just popped up and I wanted to try it:)/Oh, what email do you mean?/I have received "insider news" if you mean those emails:)"

Chat salesperson: "I am not sure if I can tell you about our news yet [ . . .]: D Just kidding. Well, we have some exciting news related to new compatibilities with your software!/Ok, nice talking to you."

Existing customer: "Okay:)/I'll stay tuned (:) So we will keep in touch! Give my greetings to everyone!: $)$

In addition, social presence as relationship maintenance emerged when buyers asked someone to contact them because they wanted to find a solution for their own customers, as illustrated below:

Existing buyer: "Hello, I tried to call you. One of my clients is in need of a solution. I think my client is interested in your services, so could you please call me? [Adds a phone number.]"

Chat salesperson: "Of course! Could you just please type your name, the name of your company, and your email address?"

Existing buyer: "Yes, of course." [Requested information provided.]

Functions of the online B2B chat for existing buyers were further analyzed. The results showed that the main functions included: searching for information, requesting further interaction with a solution seller, problem-solving, giving feedback, becoming acquainted with salespersons, bringing in another potential client and socializing (Figure 1).

\section{Discussion}

\subsection{Theoretical contribution}

Knowledge is brought to the sales and marketing field by focusing on the B2B sales context and actual observed buyer-seller online chat conversations, as most of the previous studies on digital marketing have focused on consumers and a B2C sales context (Nicolla and Teresa, 2016; Obal and Lancioni, 2013). Our results contribute to existing sales and marketing literature (Corley and Gioia, 2011), as we are the first to show how social presence is embedded in $\mathrm{B} 2 \mathrm{~B}$ online chat conversations through buyers' interactive, affective and relationship maintenance responses. Furthermore, our results show how online B2B chat had different functions for buyers in different stages in their customer relationship.

Additionally, we bring an incremental advance (Corley and Gioia, 2011) to existing B2B sales and marketing research by focusing on social presence in online B2B sales interaction in the ability of participants to project themselves socially and affectively in sales interaction. Many of the previous e-commerce studies (Gefen and Straub, 2004; Ogonowski et al., 2014) have defined social presence based on Short et al. (1976) and focused on the capacity of the website to convey a sense of human sociability and warmth (Lu et al., 2016). Our approach is different, as we focused on social presence as interaction with sellers (Caspi and Blau, 2008; Lu et al., 2016) and investigated how social presence is embedded in textbased interaction between buyers and sellers in online B2B chat. In our data, there were three buyer types: new buyers, existing prospects and existing buyers. With new buyers who were in awareness phase of the relationship (Dwyer et al., 1987), and with existing prospects who were in the exploration phase of the relationship (Dwyer et al., 1987), social presence emerged in buyers' interactive and affective responses. With existing buyers who 
were in the expansion phase of the relationship (Dwyer et al., 1987), social presence was embedded as buyers' interactive, affective and relationship maintenance responses.

Interactive social presence (Garrison et al., 2001; Garrison and Anderson, 2003; Rourke et al., 1999) was shown in most of the online chat conversations in buyers' different types of questions through which they wanted to start interaction with the seller. With all buyer types, these questions were related to sales (e.g. requesting more information on the case company's service, pricing, solutions for specific problems, asking how to make the purchase and how to contact the salesperson for further interaction). This shows that online $\mathrm{B} 2 \mathrm{~B}$ chat conversations were largely sales and exchange oriented, as has been found in studies focusing on face-to-face sales interactions (Jacobs et al., 2001).

Affective responses (Garrison et al., 2001; Garrison and Anderson, 2003; Rourke et al., 1999) emerged when buyers expressed positive or negative emotions in online chat conversations. Only new buyers gave some positive feedback to the case company; however, all buyer types focused mainly on customer complaints in their negative affective responses. Therefore, online chat is a channel via which B2B buyers can complain. Furthermore, in online chat discussions between existing buyers and sellers, the buyers also expressed selfdisclosure and voluntarily revealed personal information about themselves, which was not exchange-specific disclosure (Jacobs et al., 2001). This is an important finding, as selfdisclosure enhances social bonding between business partners (Geiger and Turley, 2005; Murphy and Sashi, 2018) and reciprocal self-disclosure improves the communication satisfaction in a relationship (Sherblom, 2020).

Furthermore, we are the first to introduce a new category of social presence in the context of online B2B sales, namely relationship maintenance. This emerged in the data as sending greetings, having small talk with the seller and in buyers' questions when they wanted to find a solution for their own customers. Previous studies have shown that when B2B relationships mature, partners have more trust and commitment in their relationship (Morgan and Hunt, 1994), and then buyers can even start to bring in new customers. Furthermore, by coming to the online chat for just small talk or sending greetings, it reveals that the social component of communication is needed in digital B2B sales, as it plays a significant role in building relationships. Social interaction can help partners to get to know each other better, build trust (Morgan and Hunt, 1994), build commitment (Dwyer et al., 1987) and also align perceptions, set expectations and improve coordination (Sheng et al., 2005).

The results further showed that functions of the online chat were related to searching for information, problem-solving, having further interaction with a seller, purchasing and giving feedback. Additionally, for existing buyers, the online chat served the function of becoming acquainted with salespersons, bringing in another potential client and socializing. The results of our study partly support previous findings related to functions of the online chat in $\mathrm{B} 2 \mathrm{C}$ context. Previously, studies have found that online $\mathrm{B} 2 \mathrm{C}$ chat has three key functions: search support, navigational support and basic decision-making related to purchasing (Chattaraman et al., 2012). Previous studies (Chattaraman et al., 2012; Truel and Connelly, 2013) have found that people use online chat to gather information from an expert as well as to reduce the time spent on a task. Searching for information was the main purpose our study identified, as well. However, B2B buyers did not use online chat for support in navigation or in basic decision-making. Instead, the functions of the online B2B chat can be described as multiple and changing depending on the buyer-seller relationship stage. This is an incremental advance to previous sales and marketing research, as we show that online chat can actually help sellers to build and even develop business relationships with buyers at different stages of the relationship. Moreover, as B2B sales are increasingly 
occurring online, a more in-depth understanding is needed of how and why B2B customer relationships evolve via computer-mediated communication in online context. The existing theoretical understanding of the phases of B2B buyer-seller relationships (Crosby et al., 1990; Dwyer et al., 1987; Palmatier et al., 2013) is based on the underlying assumption that buyers and sellers are able to communicate and negotiate frequently in face-to-face settings. This study has shown that computer-mediated communication via online B2B chat is slightly different with different types of buyers. Even though social presence emerged through interactive and affective responses with all buyers, only existing buyers expressed relationship maintenance responses. Therefore, we should further investigate different technological tools, how buyers and sellers are using them and what their influence is across the different phases of buyer-seller relationships, as Arli et al. (2018) have also pointed out. Eventually, we should build a new theoretical understanding of the development process of the buyer-seller relationship in $\mathrm{B} 2 \mathrm{~B}$ sales via computer-mediated communication in online contexts.

As services are increasingly offered via the internet, the results of this study are scientifically useful (Corley and Gioia, 2011) as they could be applied when testing if chatbots could be used for B2B sales. According to Shawar and Atwell (2005, p. 489), a chatbot is a "machine conversation system which interacts with human users via natural conversational language." Chatbots are used, for example, in place of humans in online customer service chats (Hill et al., 2015) in B2C sales. Usually customer service chatbots are based on human dialogue, and therefore, the results of this study could be used when developing chatbots for $\mathrm{B} 2 \mathrm{~B}$ sales. Yet the extent to which chatbots can be used in B2B sales needs investigation, as the $\mathrm{B} 2 \mathrm{~B}$ sales process has been known to be more complex than $\mathrm{B} 2 \mathrm{C}$ sales process (Akrout and Diallo, 2017; Dubinsky, 1981; Homburg et al., 2011). Moreover, as the results of this study showed, B2B buyers can have specific questions and problems in mind when they enter a chat room, and they might even ask for customized solutions to their problems.

\subsection{Practical contribution}

The study has several managerial implications. As our results reveal, chat salespersons were not able to help the buyers in all cases, and therefore, a more experienced salesperson should be in charge of $\mathrm{B} 2 \mathrm{~B}$ online chats or they should be at least very easily available to offer better customer service. Therefore, even though buyers entering the chat room expected to gain instant solutions to their complex problems, online chat does not seem to be the best possible communication medium for solving very complex problems and offering solutions for those problems. For successful complex B2B solution, selling a richer communication medium (such as face-to-face meetings or face-to-face video chats with an expert salesperson) would be a more suitable choice (Ogonowski et al., 2014). Even though all the chat salespersons had received sales training, it seemed not to be sufficient for the needs of B2B buyers, who demanded more professional answers and fast solutions to their problems. Therefore, the chat salespersons would need an even more in-depth understanding of the company's SaaS services and their technological aspects or they should be able to consult an expert solution seller to answer complex questions from the buyers. Furthermore, in sales training the B2B sellers could learn how to add some selfdisclosure into online sales interaction, for example, a salesperson's intimate social disclosure has been found to positively impact the quality of sales interaction (Jacobs et al., 2001). Therefore, salespersons who will be involved in online B2B chats with potential customers should be taught how to elicit social disclosure from buyers, how to respond to them and how to add some social disclosure elements to their own chat messages. Based on 
our results, the case company could also improve their customer service by considering why their customers are not getting call backs and how their internal communication is working.

All in all, the results indicate that online chat could be seen as adding value for the case company. Online chat reached both new buyers and existing ones, making it a communication channel that can bring in new customers, as well as strengthen the existing customer relationship. Chat conversations can be used to improve online stores and to enhance sales communication via an increased social presence on a company's website. Furthermore, CMC tools such as Aliwangwang (an instant message tool developed by Alibaba) have been found to be an effective way to communicating with a vast amount of customers (Lu et al., 2016), and an online chat box brings added value to sellers, as they can easily serve a larger amount of B2B customers, as they able to interact face-to-face. In the future, we need a better theoretical understanding of the impact of different technological tools on relational development across different phases of the buyer-seller relationship.

\section{Limitations}

Although our study has strengths, it has some limitations. Although the data consist of online chat conversations between 157 buyers and sellers, they were still collected from a single case company. Having data only from one case company limits the results to one type of industry. In the future, multiple case study could be conducted to investigate and compare several industries to see if there are differences in the findings. The data were collected in natural settings, which makes them more reliable than interview data (Eriksson and Kovalainen, 2008). Still, we could have combined buyer survey data or buyer interviews with our online chat data to link our results to, for example, customer satisfaction or customers' trust toward the seller. However, that can be conducted in future studies.

\section{References}

Akrout, H. and Diallo, M.F. (2017), "Fundamental transformations of trust and its drivers: a multi-stage approach of business-to-business relationships", Industrial Marketing Management, Vol. 66, pp. 159-171.

Andersen, P.H. (2001), "Relationship development and marketing communication: an integrative model", Journal of Business and Industrial Marketing, Vol. 16 No. 3, pp. 167-182.

Arli, D., Bauer, C. and Palmatier, R.W. (2018), "Relational selling: past, present and future", Industrial Marketing Management, Vol. 69, pp. 169-184.

Baxter, LA. and Braithwaite, DO. (2008), Engaging Theories in Interpersonal Communication. Multiple Perspectives, SAGE, Los Angeles.

Braun, V. and Clarke, V. (2006), "Using thematic analysis in psychology", Qualitative Research in Psychology, Vol. 3 No. 2, pp. 77-101.

Brown, JR., Weaven, SK., Dant, RP. and Crosno, JL. (2016), "Boosting the effectiveness of channel governance options: the moderationing role of relational norms", European Journal of Marketing, Vol. 50 Nos 1/2, pp. 29-57.

Caspi, A. and Blau, I. (2008), "Social presence in online discussion groups: testing three conceptions and their relations to perceived learning", Social Psychology of Education, Vol. 11 No. 3, pp. 323-346.

Chattaraman, V., Kwon, W.S. and Gilbert, J.E. (2012), "Virtual agents in retail web sites: benefits off simulated social interaction for older users", Computers in Human Behavior, Vol. 28 No. 6, pp. 2055-2066.

Corley, K.G. and Gioia, D.A. (2011), "Building theory about theory building: what constitutes a theoretical contribution?”, Academy of Management Review, Vol. 36 No. 1, pp. 12-32. 
Crosby, L.A., Evans, K.R. and Cowles, D. (1990), "Relationship quality in services selling: an interpersonal influence perspective”, Journal of Marketing, Vol. 54 No. 3, pp. 68-81.

Dubinsky, A.J. (1981), "A factor analytic study of the personal selling process", Journal of Personal Selling and Sales Management, Vol. 1 No. 1, pp. 26-33.

Dwyer, F.R., Schurr, P.H. and Oh, S. (1987), "Developing buyer-seller relationships", Journal of Marketing, Vol. 51 No. 2, pp. 11-27.

Elo, M., Benjowsky, C. and Nummela, N. (2015), "Intercultural competences and interaction schemes four forces regulating dyadic encounters in international business", Industrial Marketing Management, Vol. 48, pp. 38-49.

Eriksson, P. and Kovalainen, A. (2008), Qualitative Research in Business Studies, Sage, London.

Etemad-Sajadi, R. (2014), "The influence of a virtual agent on web-users desire to visit the company: the case of restaurant's website", International Journal of Quality and Reliability Management, Vol. 31 No. 4, pp. 419-434.

Garrison, D., R. and Anderson, T. (2003), E-Learning in the 21st Century: A Framework for Research and Practice, Routledge Falmer, London.

Gefen, D. and Straub, D.W. (2004), "Consumer trust in B2C e-commerce and the importance of social presence: experiments in e-products and e-services”, Omega, Vol. 32 No. 6, pp. 407-424.

Geiger, S. and Turley, D. (2005), "Socializing behaviors in business-to-business selling: an exploratory study from the republic of Ireland", Industrial Marketing Management, Vol. 34 No. 3, pp. 263-273.

Grayson, K. (2007), "Friendship versus business in marketing relationships", Journal of Marketing, Vol. 71 No. 4, pp. 121-139.

Haytko, D.L. (2004), "Firm-to-firm and interpersonal relationships: perspectives from advertising agency account managers", Journal of the Academy of Marketing Science, Vol. 32 No. 3, pp. 312-328.

Hill, J., Ford, W.R. and Farreras, I.G. (2015), "Real conversations with artificial intelligence: a comparison between human-human online conversations and human-chatbot conversations", Computers in Human Behavior, Vol. 49, pp. 245-250.

Hoar, A. (2015), "Death of a (B2B) salesman”, available at: http://blogs.forrester.com/andy_hoar/15-0414-death_of_a_b2b_salesman (accessed 5 August 2018).

Homburg, C., Müller, M. and Klarmann, M. (2011), "When does salesperson's customer orientation lead to customer loyalty? The differential elements of relational and functional customer orientation", Journal of the Academy of Marketing Science, Vol. 39 No. 6, pp. 795-812.

Hung, K.-P. and Lin, C.-K. (2013), "More communication is not always better? The interplay between effective communication and interpersonal conflict in influencing satisfaction", Industrial Marketing Management, Vol. 42 No. 8, pp. 1223-1232.

Jacobs, R.S., Hyman, M.R. and McQuitty, S. (2001), "Exchange-specific self-disclosure, social selfdisclosure, and personal selling", Journal of Marketing Theory and Practice, Vol. 9 No. 1, pp. 48-62.

Knapp, M., L. (1972), Nonverbal Communication in Human Interaction, Holt, Rinehart and Winston, New York, NY.

Koponen, J., Julkunen, S. and Asai, A. (2019), "Sales communication competence in international B2B solution selling", Industrial Marketing Management, Vol. 82, available at: https://oi.org/ 10.1016/j.indmarman.2019.01.009

Leek, S., Houghton, D. and Canning, L. (2017), "Twitter and behavioural engagement in the healthcare sector: an examination of product and service companies", Industrial Marketing Management, available at: http://dx.doi.org/10.1016/j.indmarman.2017.10.009

Lu, B., Fan, W. and Ahou, M. (2016), "Social presence, trust, and social commerce purchase intention: an empirical research", Computers in Human Behavior, Vol. 56, pp. 225-237. 
McLean, G. and Osei-Frimpong, K. (2017), "Examining satisfaction with the experience during a live chat service encounter - implications for website providers", Computers in Human Behavior, Vol. 76, pp. 494-508.

Mason, K. and Leek, S. (2012), "Communication practices in a business relationship: creating, relating and adapting communication artifacts through time", Industrial Marketing Management, Vol. 41 No. 2, pp. 319-332.

Morgan, R. and Hunt, S. (1994), “The commitment-trust theory of relationship marketing”, Journal of Marketing, Vol. 58 No. 3, pp. 20-38.

E-commerce B2B chat functions

Murphy, M. and Sashi, C.M. (2018), "Communication, interactivity and satisfaction in B2B relationships", Industrial Marketing Management, Vol. 68, pp. 1-12.

Nicolla, C. and Teresa, D. (2016), "Young consumer-brand relationship building potential using digital marketing", European Journal of Marketing, Vol. 50 No. 11, pp. 1993-2017.

Obal, M. (2013), "Why do incumbents sometimes succeed? Investigating the role of interorganizational trust in the adoption of disruptive technology", Industrial Marketing Management, Vol. 42 No. 6, pp. 900-908.

Obal, M. and Lancioni, R.A. (2013), "Maximizing buyer-supplier relationships in the digital era: Concept and research agenda", Industrial Marketing Management, Vol. 42 No. 6, pp. 851-854.

Ogonowski, A., Montandon, A., Botha, E. and Reyneke, M. (2014), "Should new online stores invest in social presence elements? The effect of social presence on initial trust formation", Journal of Retailing and Consumer Services, Vol. 21 No. 4, pp. 482-491.

Olson, J.S. and Olson, G.M. (2000), "I2i trust in e-commerce", Communications of the Acm, Vol. 43 No. 12 , pp. 41-44.

Ou, C.X., Pavlou, P.A. and Davison, R.M. (2014), "Swift Guanxi in online marketplaces: the role of computer-mediated communication technologies”, MIS Quarterly, Vol. 38 No. 1, pp. 209-230.

Palmatier, R.W., Houston, M.B., Dant, R.P. and Grewal, D. (2013), "Relationship velocity: toward a theory of relationship dynamics", Journal of Marketing, Vol. 77 No. 1, pp. 13-30.

Price, L.L. and Arnould, E.J. (1999), "Commercial friendships: service provider - client relationships in context”, Journal of Marketing, Vol. 63, pp. 38-56.

Reichheld, F., F. and Schefter, P. (2000), "E-loyalty: your secret weapon on the web”, Harvard Business Review, Vol. 78, pp. 105-113.

Rourke, L., Anderson, T., Garrison, D.R. and Archer, W. (1999), "Assessing social presence in asynchronous, text-based computer conferencing”, Journal of Distance Education, Vol. 14 No. 3, pp. 51-70.

Sallnäs, E.L., Rassmus-Gröhn, K. and Sjöström, C. (2000), "Supporting presence in collaborative environments by haptic force feedback", ACM Transactions on Computer-Human Interaction (Tochi), Vol. 7 No. 4, pp. 461-476.

Shawar, B.A. and Atwell, E. (2005), "Using corpora in machine-learning chatbot systems”, International Journal of Corpus Linguistics, Vol. 10 No. 4, pp. 489-516.

Sheng, S., Brown, J.R. and Nicholson, C.Y. (2005), "The mediating role of communication in interorganizational channels", Journal of Marketing Channels, Vol. 13 No. 2, pp. 51-80.

Sherblom, JC. (2020), Computer-Mediated Communication. Approaches and Perspectives, Cognella, San Diego, CA.

Short, J.A., Williams, E. and Christie, B. (1976), The Social Psychology of Telecommunications, Wiley, London.

Stanko, M.A., Bonner, J.M. and Calantone, R.J. (2007), "Building commitment in buyer-seller relationships: a tie strength perspective”, Industrial Marketing Management, Vol. 36 No. 8, pp. 1094-1103. 
EJM

54,6

Truel, O. and Connelly, C.E. (2013), "Too busy to help: antecedents and outcomes of interactional justice inn based service encounters", International Journal of Information Management, Vol. 33, pp. 674-683.

Weitz, B.A. and Bradford, K.D. (1999), "Personal selling and sales management: a relationship marketing perspective", Journal of the Academy of Marketing Science, Vol. 27 No. 2, pp. 241-254.

Yin, R., K. (2009), Case Study Research. Design and Methods, 3rd ed., Sage, Thousand Oaks.

Yoon, C. (2010), "Antecedents of customer satisfaction with online banking in China: the effects of experience”, Computers in Human Behavior, Vol. 26 No. 6, pp. 1296-1304.

\section{Further reading}

Altman, I. and Taylor, D., A. (1973), Social Penetration: The Development of Interpersonal Relationships, Holt, Rinehart and Winston, New York, NY.

Garrison, D.R., Anderson, T. and Archer, W. (1999), "Critical inquiry in text-based environment: computer conferencing in higher education”, The Internet and Higher Education, Vol. 2 Nos 2/3, pp. 87-105.

Hong, I.B. and Cha, H.S. (2013), "The mediating role of consumer trust in an online merchant in predicting purchase intention", International Journal of Information Management, Vol. 33 No. 6 , pp. 927-939.

Syam, N. and Sharma, A. (2018), "Waiting for sales renaissance in the fourth industrial revolution: machine learning and artificial intelligence in sales research and practice", Industrial Marketing Management, Vol. 69, pp. 135-146.

Walther, J.B. (1996), "Computer-mediated communication: impersonal, interpersonal, and hyperpersonal interaction”, Communication Research, Vol. 23 No. 1, pp. 3-43.

Wilson, J.M., Straus, S.G. and McEvily, B. (2006), "All in due time: the development of trust in computermediated and face-to-face teams", Organizational Behavior and Human Decision Processes, Vol. 99 No. 1, pp. 16-33.

\section{Corresponding author}

Jonna Pauliina Koponen can be contacted at: jonnapauliina.koponen@uef.fi

For instructions on how to order reprints of this article, please visit our website: 